\title{
After 20 years, prospects remain bleak for minorities in US science
}

Atlanta. The American Association for the Advancement of Science (AAAS) chose "Unity in Diversity" as the theme for its 161st annual meeting, which took place over last weekend in the home city of Martin Luther King and his still-elusive version of the American Dream.

But Atlanta is still not united, and US science is not yet diverse. Thirty years after Dr King's speech, blacks have political control of the city's shattered core. But the whites - and most of the wealth - have moved to the suburbs; and the overwhelmingly white gathering of over 5,000 AAAS members reflects 20 years of faltering efforts to make science "look more like America".

Figures recently published by the National Research Wyche: fears for the

National Research future of diversity Council show that

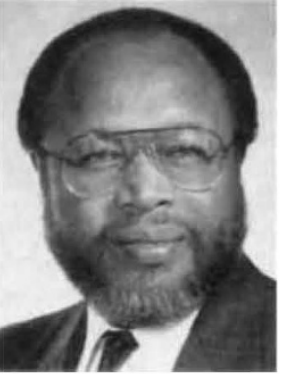

moting such policies. At a recent science policy seminar at the Massachusetts Institute of Technology, James Vincent, chief executive of the biotechnology company Biogen, said that efforts to boost diversity in science are a waste of time. We should, he said, "return to a merit-based system".

James Wyche of Brown University, Rhode Island, who organized a session on racial diversity in the sciences at the AAAS meeting, said that these events were not all bad. "There's been a change in the political and social environment in the United States, and this question is being revisited," he says. "That is not necessarily a bad thing." Some programmes, says Wyche, have been created without an adequate assessment of their effectiveness.

At the session itself, speakers argued that diversity programmes should emphasize excellence, rather than remediation. "I rarely hear of kids from remedial classes doing a PhD," said Freeman Hrabowski, president of the University of Maryland at Baltimore County, whose \$6 million Meyerhoff Scholars' programme, aimed at attracting the best minority students into science and steering them into $\mathrm{PhDs}$, has been widely acclaimed.
But it is at graduate school that the problem intensifies, according to data reported by Clifton Poodry of the National Institutes of Health (NIH). He found that, while 33 per cent of white graduate students complete their $\mathrm{PhD}$, only 14 per cent of minority students do so - a far wider disparity than at any other stage of education.

Poodry says he does not know how much this is due to the relative economic insecurity of minorities. But Hrabowski denies the suggestion that it may be irresponsible to send black students down such a rocky road. "Remember that there are thousands of economically advantaged black people in America, and there are thousands of disadvantaged minorities who are doing well in science," he points out.

The session also acknowledged the crucial requirement of leadership from prominent individuals. Only very recently has such leadership been forthcoming in science. Harold Varmus, the director of NIH, has taken a strong interest in the issue inside the institutes, and was described by Hrabowski as the "godfather" of the Meyerhoff programme.

Dan Goldin, administrator of the National Aeronautical and Space Administration per cent of all doctorates in the United States - a figure virtually unchanged since 1978. But the bulk of those doctorates were in education and social science: blacks received just over 2 per cent of life sciences doctorates in 1993, and just 41 physical sciences doctorates out of a total of 3,500. Hispanics have slightly improved their position. But both groups remain underrepresented in the outflow of science PhDs in the United States by a factor of about ten.

"The statistics are very depressing," concedes Francisco Ayala, the president of the AAAS and himself a Spanish immigrant to the US. "Despite all the efforts that have been made, representation remains very low". Although the AAAS board meeting in Atlanta was briefed on the issue, Ayala says, "the fact is we don't know the answers. Perhaps attempts have been made to patch the problem up, when systematic problems need to be approached systematically."

But the vultures are now circling over such efforts as have been made to draw blacks and Hispanics into US science. Programmes to help minority students that exclude whites have been declared illegal (although the ruling has not been enforced). A pending referendum in California could nullify the state's affirmative action programmes, and Senator Phil Gramm (Republican, Texas), a leading contender to be the next US president, has promised to do the same at the federal level - on his first day in office.

Politicians are not the only people pro-

\section{Art meets science underneath the Louvre}

Paris. The worlds of science and art collided last week with the opening of the new buildings of the Laboratoire de recherche des musées de France, in the grounds of the Louvre in Paris. Created in 1931, the laboratory has become a centre of excellence for the scientific study of collections, and the restoration of works of art - over 1,000 objects and 430 paintings pass through the laboratory every year.

The new building is likely to become recognized as a work of art itself. Built at a cost of FF155 million (US\$30 million), the Parisian daylight saturates its $5,000 \mathrm{~m}^{2}$ of underground floors arranged on three levels around a vast central shaft - through a massive glass slab supported by solid glass beams, themselves an architectural first.

Besides the $X$-ray, infrared and ultraviolet radiation techniques used to unravel the history behind the surface of objects, the centre's 60 researchers are also equipped with a 2 MV electrostatic particle accelerator 'AGLAE'. Its three neutron beams allow the non-destructive chemical analysis

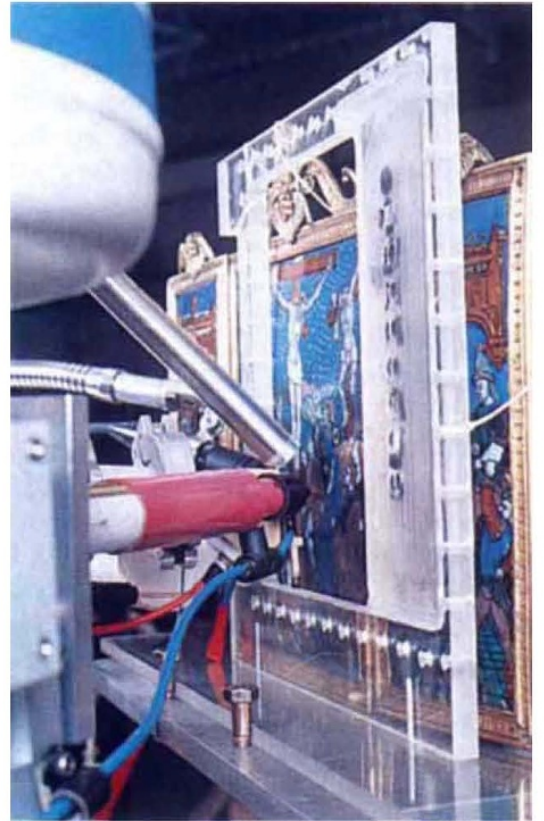

of objects, for example the study of the colours of glass used in the triptyque of "The Crucifixion" (see above), made of enamel on copper in Limoges around AD 1500. 